\title{
Effect of fiber volume fraction to tensile strength in com- posites polyester reinforced Sugar Palm Fiber (SPF)
}

\author{
Fatkhurrohman ${ }^{1 *}$, Zunairoh ${ }^{2}$ \\ ${ }^{1}$ Gadjah Mada University, Yogyakarta, Indonesia \\ 2 Airlangga University, Surabaya, Indonesia
}

\section{Keywords \\ Composites polyester SPF \\ Fiber volume fraction Tensile strength}

Received: 3 October 2018 Accepted: 7 November 2018 Published: 19 December 2018

\begin{abstract}
Manufacturing of eco-friendly composites has been increased due to recyclability and biodegradability factors. The effect of fiber volume fraction on tensile strength in composites polyester-reinforced sugar palm fiber (SPF) has been studied experimentally. This study aim is to investigate the effect of fiber volume fraction on tensile strength of composites polyester-reinforced sugar palm fiber (SPF) and fracture failure after tensile testing, and then these data results can be used as references on manufacturing industries such as boat building, which are expected can be replaced with composite polyester reinforced by SPF. Sugar palm fiber (SPF) is soaked in an alkaline solution of $5 \% \mathrm{NaOH}$ for 2 hours, then composites laminate with five different fiber volume fractions were fabricated with hand lay-up and press molding and tested under tensile loads respectively, for the tensile test specimen, refer to the standard ASTM D-638. The test result showed that the highest tensile strength was obtained in the fiber volume fraction of $40 \%$, amounting to $24.65 \mathrm{MPa}$ and the elongation has obtained $7.73 \%$, while the lowest tensile strength has obtained in the fiber volume fraction of $20 \%$ amounting to $17.55 \mathrm{MPa}$ and the elongation has obtained $4.41 \%$. Based on the result and analysis use single-way ANOVA, it can be concluded that the composite polyester-reinforced sugar palm fiber (SPF) has the optimum tensile strength on the fiber volume fraction of $40 \%$ and fiber volume fraction has an influence on the tensile strength of composite polyester-reinforced SPF. After tensile testing, fracture failure and cross-sectional shape of composite material showed that there are two types of failure, namely fiber pull out and delamination that indicates the bond between fiber and matrix is weak.
\end{abstract}

(C) 2018 The Author(s). Published by TAF Publishing.

\section{INTRODUCTION}

Composite material ability which is easily formed as needed, both in terms of strength and superiority of other properties, encourages the use of polymer composite materials as alternative materials or substitutes for conventional metal materials in various products produced by manufacturing industry, such as making boat.

Development of composite material is increasingly widespread in various areas so that also need innovation continuously. Composites with natural fiber as one example, natural fiber is used because natural fiber is abundant availability, lightweight, good corrosion resistant, good water resistant, interesting performance and no expert machining process $[1,2]$. Fiber as a reinforcing element greatly determines the mechanical properties of composite materi- als because it continues the load distributed by the matrix. Orientation, dimension, and fiber material are factors that influence the mechanical property of the composite. SPF is one of the best natural fiber because it has some benefits, such as durability to hundreds and more years, good corrosion resistant because it can hold against acid and salt water, prevent for termite, and it can also be as a shield radiation nuclear [2].

The use of natural fiber is expected to be able to replace the use of synthetic fiber even though they cannot completely replace them. at least the use of natural fiber can reduce environmental pollution from waste made and the use of nonrenewable sources. Previous research has been done using SPF given immersion treatment in $\mathrm{NaOH}$ solution to bending strength, the result of immersion treatment in $\mathrm{NaOH}$

\footnotetext{
${ }^{*}$ Corresponding author: Fatkhurrohman

†email: fatkhurhero@gmail.com
} 
solution for 2 hours can increase the bending strength of composite material reinforced SPF amount $176.77 \mathrm{MPa}$ $[1,3]$. The bending strength of composite polyester reinforced SPF with variations in fiber volume fraction has also been carried out. The results showed that the highest bending strength was found at $40 \%$ fiber volume fraction of $0.3211 \mathrm{~J} / \mathrm{mm}^{2}[4,5]$. So that further research is needed to investigate the effect of fiber volume fraction on the tensile strength of composite polyester reinforced SPF, with soaking SPF in $\mathrm{NaOH}$ solution for 2 hours.

Continuous boat building using wood raw materials can trigger deforestation because logging is carried out sustainably and can lead to illegal logging, so a replacement material is needed for boat building. the use of composite materials reinforced SPF is a wise step to be an alternative choice in replacing the raw materials of wood. The other hand the use of SPF still needs to be optimized, so that the use of wood as raw material for boats can be reduced. Sustainability of the forest system will be maintained and avoid landslides due to deforested forests.

The use of composite polyester materials reinforced by SPF is expected to replace wood as a raw material for boat building. Before composites polyester reinforced SPF is applied to the manufacture of boats it is necessary to do tensile testing first because later the composite material will be exposed to the tensile load of the sea wave. in addition, this test was conducted to investigate the maximum tensile strength of composites polyester reinforced by SPF.

Other benefits to be gained from this research enrich the properties of polyester composites by strengthening palm fiber to enrich science and technology, increasing the economic value of fiber agricultural products turning waste into high-value commercial products, and helping industries that use composite materials in terms of increasing technology of composite materials used.

\section{LITERATURE REVIEW}

\section{A. Composites Material Theory}

Definition of composite material means consisting of two or more different materials which are combined or mixed macroscopically into a useful material. According to [6], composite is a combination of materials selected based on a combination of the physical properties of each constituent material to produce new material with unique properties compared to the properties of raw material before being mixed and surface bonding occurs between each constituent material. From the mixture, composite materials will be produced which have mechanical properties and different characteristics from the forming material.
Composite materials generally consist of two elements, namely fiber as a filler and binder fiber, called matrices. In composites the main element is fiber, while the binding material uses polymer materials that are easy to form and have high binding power. Use of own fiber to determine the characteristics of composite materials, such as: stiffness, strength and other mechanical properties. As fiber filler material is used to hold most of the forces acting on composite materials, the matrix itself has a function to protect and bind fiber in order to work well against the forces that occur. Therefore, for fiber from composites, strong, rigid and brittle materials are used, while matrix materials are selected for materials that are tough, soft and resistant to chemical treatment $[7,8]$.

\section{B. Matrix}

The matrix in the composite functions as a fiber binder into a structural unit, protecting the fiber from external damage, continuing or moving external loads on the shear plane between fiber and matrices. Fiber composites must also have the ability to withstand high voltages, because fiber and matrices interact and in the end a voltage distribution occurs. Such capabilities must be possessed by the matrix and fiber in a composite material. The thing that affects the strength of the bond between the matrix and fiber is the presence of voids, voids, namely the presence of gaps in the fiber or the shape of the fiber that is less than perfect so that the matrix will not be able to fill the space in the mold. If the composite receives a load, then the stress area will move to the void area so that it will reduce the strength of the composite [9]. Unsaturated Polyester Resin is a type of thermoset resin, in some studies this resin is called polyester only. Polyester is a liquid resin with a relatively low viscosity. This resin has the property of hardening at room temperature with the use of a catalyst without producing gas when setting up like many other types of resins. In addition, the characteristics of this resin are stiff and brittle. According to [10] for its thermal properties, polyester has a lower thermal deformation temperature than other thermoset resins, because many contain styrene monomers and heat resistance if they are in the range of $110-140^{\circ} \mathrm{C}$. Polyester also has better cold resistance and electrical properties among other thermoset resins.

\section{C. $S P F$}

According to [6], fiber in the composite usually uses materials that are stronger than the matrix because filler functions as an amplifier and is the main load bearer of the composite. To obtain a strong composite must be able to place the fiber 
correctly. SPF is a natural fiber produced from sugar palm trees, usually found at the base and midrib of the leaves of the palm tree. Sugar palm fiber in Latin is known as arrenge pinnata. Sugar palm trees produce fiber in the last 4-5 years. Good sugar palm fiber is obtained from old sugar palm trees, but before fruit bunches appear (around the age of 4 years of palm trees), because when fruit bunches appear, fiber is small and bad. According to [11], fiber produced by palm trees have physical properties, among others, in the form of black threads (fiber), diameter less than $0.5 \mathrm{~mm}$, rigid and ductile (not easily broken).

\section{Fiber Volume Fraction Theory}

Comparison of composition between matrix and fiber is a determining factor in providing the strength characteristics of the composite material produced. This comparison can be shown in the form of fiber Volume Fraction (Vf).

The number of comparisons that are usually used in making composites is the ratio of weight (weight fraction) and volume ratio (volume fraction), this is because the units of ordinary matrix and fiber are calculated by units of mass and units of volume [4].

To calculate the volume fraction of fibers and matrices in a composite material can be calculated using the following equation:

$$
\begin{aligned}
\mathrm{V}_{\text {serat }} & =\frac{\text { Volume Serat }}{\text { Volume Komposit }} \times 100 \%[12] \\
\mathrm{V}_{\text {serat }} & =\frac{m f / \rho f}{\left(\frac{m f}{\rho f}\right)+\left(\frac{m m}{\rho m}\right)} \times 100 \% \\
V_{\text {matiks }} & =\frac{\text { Volume matriks }}{\text { Volume Komposit }} \times 100 \%[12] \\
\mathrm{V}_{\text {mattiks }} & =\frac{m m / \rho m}{\left(\frac{m f}{\rho f}\right)+\left(\frac{m m}{\rho m}\right)} \times 100 \%
\end{aligned}
$$

Where,

$m f=$ mass of fiber $(\mathrm{gr})$

$\rho f=$ density of fiber $(\mathrm{gr} / \mathrm{mm} 3)$

$m_{m}=$ mass of matric (gr)

$\rho_{m}=$ density of matric $(\mathrm{gr} / \mathrm{mm} 3)$

\section{E. Tensile Strength Theory}

The mechanical properties of materials are the relationship between the response or deformation of the material to the load acting. Mechanical properties related to strength, hardness, tenacity, and stiffness. Materials can be loaded in three ways, namely by tensile testing, press testing, and shear testing [13]. The value of tensile stress can be calculated using the formula as follow [13]:

$\sigma=\frac{P}{A}$

Where, $\sigma=$ Tensile strength (Pa) [13]

$\mathrm{P}=\operatorname{Load}(\mathrm{N})$

$A=$ Cross section area $\left(\mathrm{m}^{2}\right)$

The tensile strain value $(\varepsilon)$ of the material can be formulated using equations [13]:

$\varepsilon=\frac{\Delta L}{L}$

Where

$\varepsilon=$ Tensile strain $(\%)$

$\Delta \mathrm{L}=$ Length increase $(\mathrm{mm})$

$\mathrm{L}=$ Length $(\mathrm{mm})$

\section{F. Relevant Research}

Research on composite materials reinforced SPF has been widely carried out, according to [1], conducted that composite polyester reinforced SPF has the optimum bending properties for a long time soaking 2 hours in $\mathrm{NaOH}$ solution. While other studies regarding the effect of alkali treatment on composite strength were also carried out by [14] conducted that the jute epoxy fiber composite with alkali treatment had a dance strength of $19.58 \mathrm{MPa}$, whereas for the non-alkaline treatment it had a tensile strength of 12.79 MPa. From these two studies, it was found that SPF immersion in $\mathrm{NaOH}$ solution can increase the strength of composite materials reinforced by SPF.

Another study using SPF was a study conducted by [4], The results showed that increasing the volume fraction will increase the impact strength, but the subsequent decline. The longer the alkali treatment will reduce the impact strength because the fiber has undergone treatment. The impact strength maximum of the composites with fiber volume fraction of $40 \%$ and without alkaline immersion of 0.3211 $\mathrm{J} / \mathrm{mm}^{2}$. So further research is needed regarding the tensile strength of composite polyester reinforced SPF by immersion in $\mathrm{NaOH}$ solution for 2 hours.

\section{EXPERIMENTAL PROCEDURES}

The sugar palm fiber can be obtained by cutting the base of the leaf midrib, then the palm fiber in the form of a woven plate, then released or broken down using a machete. The new palm fiber platters are released from the palm tree, they still contain sticks - palm fiber sticks and then separated from the fiber of palm fiber by hand. To filter sugar palm fiber from various impurities and to separate the size of sugar palm fiber uses a sieve to a size of 30-50 mesh. For the samples used in the tensile test the fibers of length $5 \mathrm{~cm}$ are taken. Sugar palm fiber is soaked in an alkaline solution of $5 \% \mathrm{NaOH}$ for 2 hours then cleaned with water, then dried naturally in the room without being exposed to sunlight for 48 hours, steaming at $60^{\circ} \mathrm{C}$ to remove moisture in the fiber. Then sugar palm fiber is ready to be used to make polyester composite materials with resin unsaturated polyester (UPRs) type 157 BQTN and hardener metal ethyl ketone peroxide (MEKPO). 


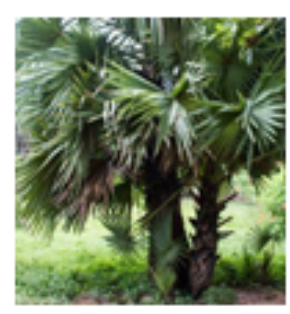

(a)



(b)

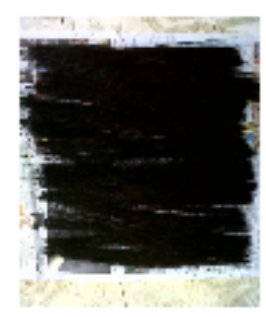

(c)

Fig. 1. (a) Sugar palm tree; (b) SPF; (c) SPF ready to use

Manufacturing of composite materials is made with hand lay-up and pressing methods. The manufacture of composite materials was carried out with a variation of fiber volume fraction of $20 \%, 30 \%, 40 \%, 50 \%$, and $60 \%$.

The process of making composite materials is carried out by pouring the matrix in the mold evenly and followed by giving the fiber until the entire matrix moistens each fiber evenly. The direction of sugar palm fiber orientation is random. The final stage of printing is by pressing using a hydraulic jack for 24 hours, after which the composite material is removed from the mold. Composite material that has been finished is then cut using a saw so that it becomes a tensile test sample in accordance with ASTM D 638 standard. The finished test sample is finished heating in an oven at a temperature of $60^{\circ} \mathrm{C}$ for 4 hours. This is done to accelerate the reaction process of the ester chain in the composite material. Then the test sample already to test the tensile strength using Universal Testing Machine that has a capacity 60 ton.

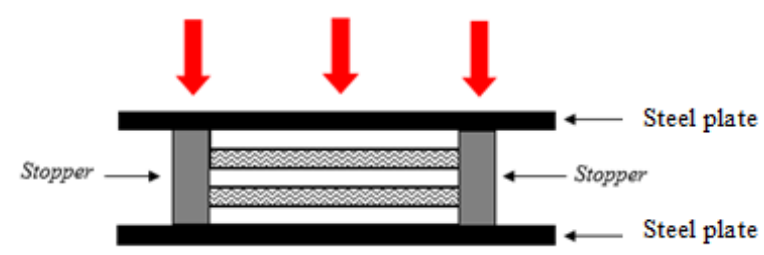

Fig. 2. Schematic illustration of press molding composite

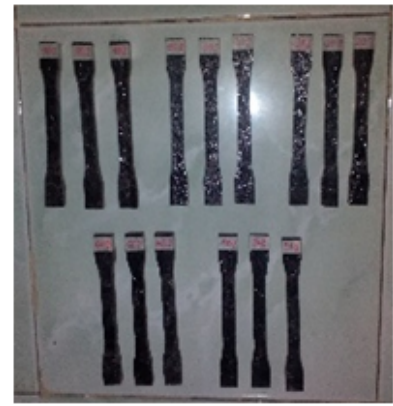

Fig. 3. Specimens were ready to be tested

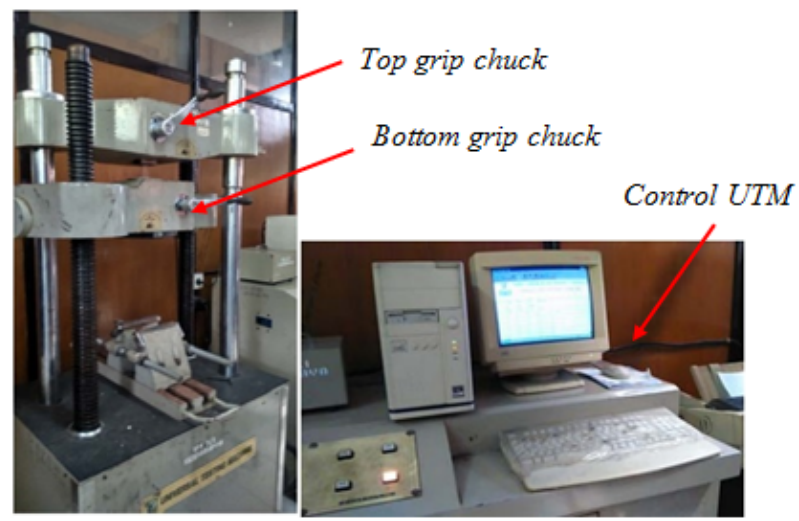

Fig. 4. Universal Testing Machine (UTM)

\section{RESULTS}

\section{A. Analysis of Tensile Test (ANOVA)}

The collected test results data then processed using the single-way ANOVA with SPSS 23. The single ANOVA test results on the effect of fiber volume fraction on the tensile strength of polyester composites reinforced by SPF seen from several pices of evidence of differences between variants. Before conducting a single ANOVA test the results of the research must be based on the assumption that the data to be issued is normally distributed, the variance of each data is the same (homogeneous) and the sample is not related to one another. Normality and homogeneity tests are carried out so that the validity data is fixed and the results 
of a single ANOVA method can be done correctly. After the data are declared normal distribution and each variable is homogeneous, then a single ANOVA test can be carried out. 1) Data normality test: In testing the normality there are two types of normal data distribution test equipment, namely, Kolmogorov-Smirnov and Shapiro-Wilk. Based on testing using Shapiro-Wilk, each data obtained a level of significance or probability value above 0.05 ; it can be said that the data distribution of each variable is normal.

TABLE 1

TESTS OF NORMALITY

\begin{tabular}{|c|c|c|c|c|c|c|}
\hline \multirow[t]{2}{*}{ Sample Test } & \multicolumn{3}{|c|}{ Kolmogorov-Smirnov ${ }^{\mathrm{a}}$} & \multicolumn{3}{|c|}{ Shapiro-Wilk } \\
\hline & Statistic & $d f$ & Sig. & Statistic & $D f$ & Sig. \\
\hline $20 \%$ & .284 & 3 & & .934 & 3 & 0.503 \\
\hline $30 \%$ & .260 & 3 & & .958 & 3 & .605 \\
\hline $40 \%$ & .177 & 3 & & 1.000 & 3 & .968 \\
\hline $50 \%$ & .301 & 3 & & .912 & 3 & .424 \\
\hline $60 \%$ & .359 & 3 & & .810 & 3 & .138 \\
\hline
\end{tabular}

2) Data homogeneity test: From Table 2, the Levene Statistic value is 1.568 with a significance value of 0.257 . This shows that the significance value is more than 0.05 , so it can be said that the results of the homogeneous tensile test (uniform).

TABLE 2

TEST OF HOMOGENEITY OF VARIANCES

\begin{tabular}{llll}
\hline \hline Levene Statistic & df1 & df2 & Sig. \\
\hline 1.568 & 4 & 10 & .257 \\
\hline \hline
\end{tabular}

3) Single ANOVA test: This single ANOVA test was used to determine whether there was a significant difference between the volume fraction fiber to tensile strength. The significant difference in question is the difference between the average calculated test data, in this study the difference in volume fraction of fiber used in polyester composites. The tensile test results obtained from the UTM machine are then processed using a single ANOVA method through the SPSS 23. The single ANOVA test results can be explained as follows.

TABLE 3

TESTS OF NORMALITY

\begin{tabular}{llllll}
\hline \hline & Sum of Squares & Df & Mean Square & $F$ & Sig. \\
\hline Between Groups & 1.066 & 4 & .266 & 4.732 & .021 \\
Within Groups & .563 & 10 & .056 & & \\
Total & 1.629 & 14 & & & \\
\hline \hline
\end{tabular}

\section{B. Effect of Fiber Volume Fraction on Tensile Strength of Polyester Composites Reinforced SPF}

The highest ultimate tensile strength obtained in fiber volume fraction of $40 \%$, the ultimate tensile strength is 24.65
$\mathrm{MPa}$ and the lowest ultimate tensile strength obtained in fiber volume fraction of $20 \%$, the ultimate tensile strength is $17.55 \mathrm{MPa}$.



Fig. 5. The curve relationship a fiber volume fraction with tensile strength 


\section{Effect of Fiber Volume Fraction on Elongation of Polyester Composites Reinforced SPF}

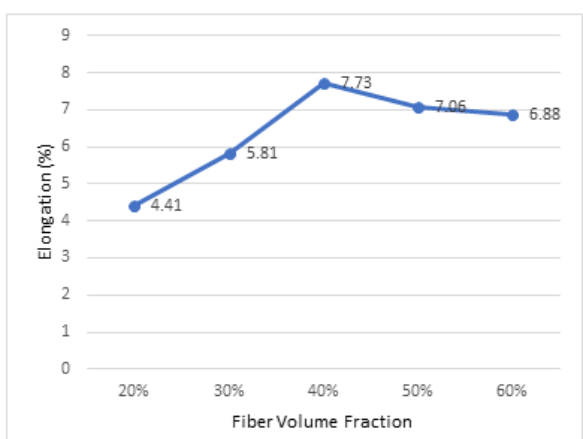

Fig. 6. The curve relationship a fiber volume fraction with elongation

The highest elongation at $40 \%$ fiber volume fraction with elongation is $7.73 \%$, while polyester composites that have the lowest elongation at $20 \%$ fiber volume fraction with elongation are $4.41 \%$.

\section{Photos of Mechanism and Cross-Sectional Fracture}

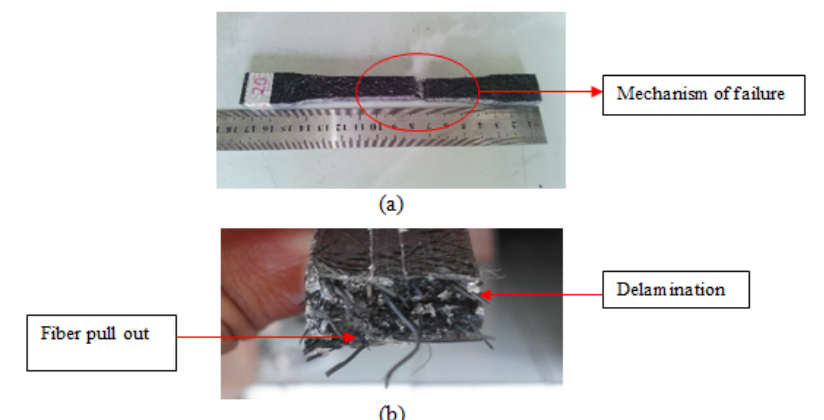

Fig. 7. Fracture test sample fiber volume fraction $20 \%$ (a) Mechanism of failure (b) Cross-section failure

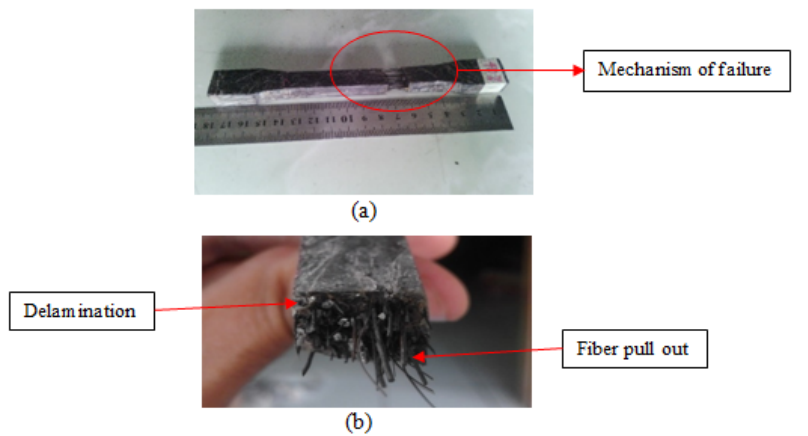

Fig. 8. Fracture test sample fiber volume fraction 40\% (a) Mechanism of failure (b) Cross-section failure

\section{DISCUSSION}

Fiber volume fraction influences the tensile strength of composites polyester reinforced Sugar Palm Fiber (SPF). This is evidenced by analysis using single-way ANOVA and from Figure 5 and Figure 6. It can be seen from figure 5, the average tensile strength of each fiber volume fraction, starting from the fiber volume fraction of $20 \%$ has the ultimate tensile strength of $17.55 \mathrm{MPa}$, the fiber volume fraction of $30 \%$ has the ultimate tensile strength of $20.82 \mathrm{MPa}$, fiber volume fraction of $40 \%$ has the ultimate tensile strength of $24.65 \mathrm{MPa}$, fiber volume fraction of $50 \%$ has the ultimate tensile strength of $24.06 \mathrm{MPa}$ and fiber volume fraction of $60 \%$ has the ultimate tensile strength of $23.34 \mathrm{MPa}$. The highest ultimate tensile strength obtained in fiber volume fraction of $40 \%$, the ultimate tensile strength is 24.65 $\mathrm{MPa}$ and the lowest ultimate tensile strength obtained in fiber volume fraction of $20 \%$, the ultimate tensile strength is $17.55 \mathrm{MPa}$. It can be seen that fiber volume fraction give effect to tensile strength in composites polyester reinforce SPF. However, this condition only applies in fiber volume fraction $20 \%$ until $40 \%$, in $50 \%$ and $60 \%$ the tensile strength will be decrease.

Based on the support of previous research [10] that conducted maximum tensile strength in composite materials with random fibers, it was found to at $40 \%$ fiber volume fraction of 12, $62 \mathrm{MPa}$. It was also stated in this study that the type of fiber arrangement, fiber volume fraction, and chemical treatment, namely soaking fiber with $\mathrm{NaOH}$ (alkaline solution) can increase the tensile strength of composite materials but only at $40 \%$ fiber volume fraction, then in $50 \%$ and $60 \%$ tensile strength will be decrease.

From Figure 6, it can see that elongation each fiber volume fraction of tensile test samples has several differences, it can be obtained by polyester composites which have the highest elongation at $40 \%$ fiber volume fraction with elongation is $7.73 \%$, while polyester composites that have the lowest elongation at $20 \%$ fiber volume fraction with elongation is $4.41 \%$. While for $30 \%$ fiber volume fraction has an elongation is $5.81 \%$, for a fiber volume fraction of $50 \%$ has an elongation is $7.06 \%$, and for fiber volume fraction of $60 \%$ has an elongation is $6.88 \%$.

From Figure 7 and 8, it can be concluded that composite materials with $40 \%$ fiber volume fraction have the highest tensile strength and elongation, it is $24.65 \mathrm{MPa}$ and $7.73 \%$. Composite materials with $20 \%$ fiber volume fraction have the lowest tensile strength and elongation, it is $17.55 \mathrm{MPa}$ and $4.41 \%$. So that it can be said that there is an effect of fiber volume fraction on the tensile strength of polyester composites reinforced SPF, this is also supported by data analysis using the one-way ANOVA method test using SPSS 23 software calculated in analysis of tensile strength test section.

The purpose of macro photography is to determine the fail- 
ure that occurs in the composite. In addition, macro photographs were also carried out to see the fracture characteristics of the tensile test results on the composite. In the cross section of the polymer composites reinforced SPF caused by the tensile load seen fiber pull out. This is due to the release of fibers from the matrix before the composite is broken at the time of tensile testing. In areas that have the weakest adhesion bond between fibers and matrices in the composite, the fibers are separated from the matrix resulting in fiber pull out. In addition to the fiber pull out cross-section, there is also a cross-sectional shape in the form of delamination, which is between the fiber layers and the composite matrix is damaged in the form of small fragments and the fragments are separated from the fiber. This is because the bond between the matrix and fiber is homogeneous, so the matrix cannot be separated from the fiber, but the matrix breaks because the tensile load it receives exceeds the limit of its tensile strength, and the resulting fractions are in small pieces.

\section{CONCLUSION}

In this study, the effect of fiber volume fraction on the tensile strength in composites polyester reinforced SPF was investigated through the experimental and analytical methods. The flexural failure modes were examined through photo macroscopic. Within its limitation, the conclusion of this research is the tensile strength of polyester composite material reinforced SPF with fiber volume fraction of $20 \%, 30 \%$,
$40 \%$ has increased with increasing fiber volume fraction, but at $50 \%$ and $60 \%$ fiber volume fraction composite tensile strength decreased. For the highest tensile strength obtained at $40 \%$ fiber volume fraction which is equal to 24.65 $\mathrm{MPa}$, while for the lowest tensile strength obtained at $20 \%$ fiber volume fraction which is equal to $17.55 \mathrm{MPa}$. This shows that fiber volume fraction influences on the tensile strength of polyester composites reinforced SPF, it is supported also by analytical using ANOVA testing using SPSS 23 software.

The shape of the cross section of the composite polyester reinforced SPF after destructive testing by conducting a tensile test by conducting a macro photo is known to form a failure that is in the form of fiber pull out or loose fiber from the composite and delamination or matrix damaged in small pieces because the matrix is not able to withstand the tensile load given.

Future research is expected to be able to test the results of failure using SEM and minimize voids in the composite that will be made, so that it will increase the strength of the composite by using a better press.

\section{ACKNOWLEDGMENT}

The Authors wish to thank Lembaga Pengelola Dana Pendidikan (LPDP) Scholarship for providing and supporting Authors to attend in Global Issues in Multidisciplinary Academic Research (GIMAR) 2019 in Japan.

\section{REFERENCES}

[1] M. A. Irfai, D. Wulandari, E. Marsyahyo et al., "Effect of naoh treatment on bending strength of the polyester composite reinforce by sugar palm fibers," in IOP Conference Series: Materials Science and Engineering, New York, NY. IOP Publishing, 2018.

[2] P. Truttim and P. Sohsalam, "Comparison of electrocoagulation using iron and aluminium electrodes for biogas production wastewater treatment," Journal of Advances in Technology and Engineering Research, vol. 2, no. 2, pp. 35-40. doi: https://doi.org/10.20474/jater-2.2.2

[3] M. Usman and W. M. S. Wan Daud, "Production of synthesis gas by utilization of municipal solid waste via dry reforming of methane," International Journal of Technology and Engineering Studies, vol. 1, no. 1, pp. 1-7, 2015. doi: https://doi. org/10.20469/ijtes.40001

[4] B. M. N. Rahman, B. Riyanta, and K. Diharjo, "The effect of fiber volume fraction and long immersion in alkali for impact strength composite palm fiber-polyester," Journal Ilmiah Semesta Teknika, vol. 14, no. 1, pp. 26-32, 2011.

[5] B. R. Koh, Y. Hun Oh, and D. Park, "A study on formation of saltwater-freshwater interface and upconing in coastal aquifers based on experiments with hydraulic models," Journal of Advances in Technology and Engineering Studies, vol. 2, no. 5, pp. 134-139, 2016. doi: https://doi.org/10.20474/jater-2.5.1

[6] R. F. Gibson, Principles of composite material mechanics. New York, NY: CRC Press, 2016.

[7] F. R. Jones, Mechanic of Composite Material. New Jersy, NJ: Taylor \& Francis, 1994.

[8] P. Widya, S. Tulus, K. P. Nadira, and S. Nelson, "A tofu wastewater treatment using combination of plasma electrolysis and coagulation-flocculation method," International Journal of Technology and Engineering Studies, vol. 4, no. 1, pp. 42-49, 2018. doi: https://doi.org/10.20469/ijtes.4.10001-2 
[9] M. M. Schwartz, Composite Material Handbook. Singapore: McGraw Hill, 1984.

[10] N. Bukit and E. Frida, "Pengaruh fraksi volume serat ijuk dan serat sabut kelapa sebagai bahan komposit hibrid," Jurnal Saintech, vol. 2, no. 3, pp. 77-83, 2010.

[11] U. B. Surono, "Analisa sifat fisis dan mekanis komposit serat ijuk dengan bahan matrik poliester," in Prosiding Seminar Nasional ReTII, Bandung, Indonesia, 2017.

[12] V. V. Vasiliev and E. V. Morozov, Mechanics and Analysis of Composite Materials. New York, NY: Elsevier, 2001.

[13] W. Suherman, "pengetahuan bahan," Jurusan Teknik Mesin Institut Teknologi Sepuluh Nopember, Surabaya, Indonesia, Unpublished master's thesis, 1987.

[14] M. Owen, "The effects of alkali treatment on the mechanical properties of jute fabric reinforced epoxy composites," International Journal of Fiber Text Res, vol. 4, no. 6, pp. 32-40, 2014. 